\title{
Lymphatic Invasion Assessment
}

National Cancer Institute

\section{Source}

National Cancer Institute. Lymphatic Invasion Assessment. NCI Thesaurus. Code

C127766.

An evaluation of the presence or degree of lymphatic invasion present in a sample. 